\title{
Réquiem por Istria: la pérdida de la Italia balcánica en la obra de Fulvio Tomizza
}

\author{
Roberto GÓMEZ MARTÍNEZ \\ Departamento de Filología Italiana \\ Universidad Complutense de Madrid \\ robertogmtinez@gmail.com
}

\begin{abstract}
RESUMEN
Una de las muchas consecuencias de la II Guerra Mundial fue el trazado de nuevas fronteras. Así, numerosos territorios pasaron a formar parte de otros estados. Es el caso de la península de Istria que, siendo italiana desde el final del primer contingente, pasó a Yugoslavia en 1954. Por este motivo, los cientos de miles de italianos que allí vivían tuvieron que elegir entre el exilio en Trieste o vivir bajo el nuevo régimen comunista del mariscal Tito como una minoría étnica. Este panorama político-social es el que retrata Fulvio Tomizza, cuya obra es un réquiem por la tierra perdida.
\end{abstract}

Palabras clave: Istria, Yugoslavia, Trieste, exilio, Italia balcánica.

\section{Requiem for Istria: the loss of Balkan Italy in Fulvio Tomizza's Works}

\begin{abstract}
One of the main consequences of the II World War was the design of new borders. Thus, many territories became part of other states. This is the case of the peninsula of Istria, Italian from the end of the first contingent and included into Yugoslavia in 1954. For this, hundreds of thousands of Italians who lived there had to choose between the exile in Trieste and a life under the new Communist regime of Marshal Tito as an ethnic minority. In this social and political context Fulvio Tomizza's works take place, as a requiem for the lost land.
\end{abstract}

Keywords: Istria, Yugoslavia, Trieste, exile, Balkan Italy.

Situada al norte del mar Adriático y puerta geográfica a los Balcanes, la península de Istria ${ }^{1}$ ha jugado siempre un papel importante en la Historia. A ojos de Occi-

\footnotetext{
1 Tras la Segunda Guerra Mundial, Istria estaba repartida entre Italia (municipalidad de Muggia) y Yugoslavia. Con la desintegración de este país en 1991, la región se reparte, además, entre Eslove- 


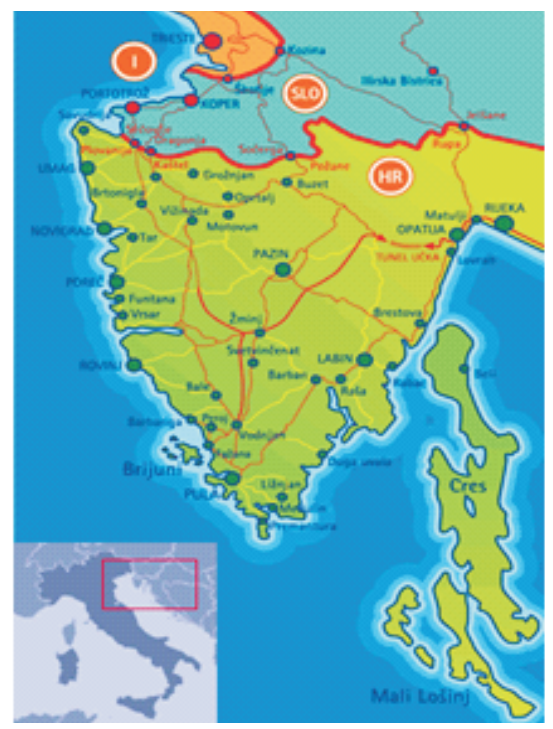

dente, la región fue vista como un cruce de caminos y, especialmente a comienzos de la Edad Moderna, como una atalaya para frenar el avance del Imperio Otomano. Así la consideró la República de Venecia, que aprovechó el territorio para expandirse hasta Grecia. Es por esta presencia plurisecular por la que la herencia veneciana está aún vigente en la península, no solo en la cultura y arquitectu$\mathrm{ra}$, sino también en los dialectos vénetos existentes, lo que provocaría más tarde el acercamiento a la Italia unificada.

Será con Napoleón y el Tratado de Campoformio en 1797 cuando la Serenissima deje de existir e Istria pase a formar parte de Austria (Tomaz 2007: 234), cambiando radicalmente de ambiente, esta vez germánico y centroeuropeo. En este período la flota naval austríaca se asienta en el Puerto Franco de la vecina Trieste, ciudad que, si bien geográficamente no forme parte de la península, ha compartido siempre una historia común con la misma.

Con la Unificación de Italia en 1861 se crea un estado único para los pueblos de cultura y dialectos italianos. Sin embargo, territorios como Trieste e Istria no se anexionaron a la recién creada nación, lo que provocó el nacimiento de sentimientos irredentistas que llegarían a su máximo apogeo en la Primera Guerra Mundial, conflicto que Italia aprovecharía para declararle la guerra Austria en 1915 (Tomaz 2007: 283).

Al final del contingente, con la derrota y desaparición del Imperio Austrohúngaro, tanto Trieste como la Península (incluyendo la ciudad de Rijeka, en italiano Fiume), así como la ciudad dálmata de Zadar (Zara) (Tomaz 2007: 290), fueron anexionadas al Reino de Italia, produciéndose la italianización masiva de estos territorios balcánicos, desprestigiando e incluso penalizando el uso de las lenguas eslavas en favor del italiano. Es por este motivo que, con el estallido de la Segunda Guerra Mundial, esta región de población mixta sufriría numerosas venganzas personales y de limpieza étnica entre italianos y eslavos.

Con el armisticio de Italia el 8 de septiembre de 1943, Trieste e Istria son ocupadas por tropas de la Alemania nazi y, al final de la Guerra, la gran mayoría de la Península pasaría bajo dominio yugoslavo. Trieste se convierte en una ciudad-estado denominada Territorio Libre de Trieste y separada en dos zonas: la zona A, bajo jurisdicción angloamericana, ocupa Trieste y parte de su provincia, incluyendo Muggia, municipalidad istriana; la zona B, bajo jurisdicción yugoslava, ocupa la

nia y Croacia (SLO y HR en la imagen). Según algunos geógrafos, la Península Balcánica es el territorio comprendido al sur de la línea imaginaria dibujada entre Trieste (Italia) y Odessa (Ucrania), por lo que Istria sería una puerta de entrada a los Balcanes (Hajdú 2007: 4). 


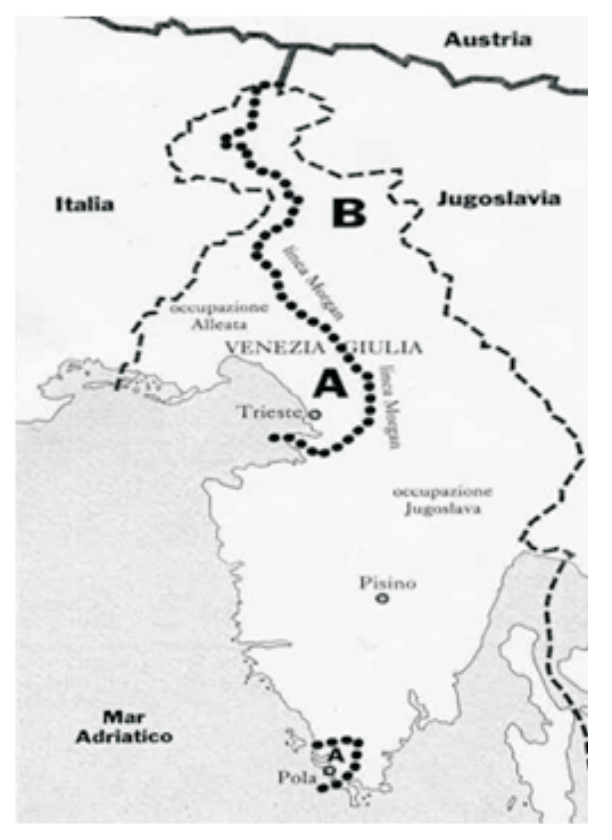

parte nororiental de Istria. En 1954, con el denominado Memorándum de Londres, los gobiernos de Roma y de Belgrado firman el fin del Territorio Libre de Trieste y se dividen las dos zonas del extinto estado, pasando a Italia la zona A y a Yugoslavia la Zona $\mathrm{B}$, algo que se haría definitivo en el Tratado de Osimo de 1975 (Tomaz 2007: 292).

De este modo, además del drama de la separación en dos naciones, el pueblo istriano que permaneció en la Zona B tuvo que convivir con el nuevo régimen comunista instaurado por el mariscal Tito en Yugoslavia, lo cual, junto a la identidad italiana de muchos de los habitantes de la Península, afectaba también a la propiedad privada y a la identidad religiosa. Por este motivo, muchos italianos de la Zona B, apoyados e incluso motivados por el Gobierno yugoslavo, que salvaguardaba la unión de los eslavos del Sur, optaron por refugiarse en Trieste, apenas a unos kilómetros de su tierra natal, pero en un estado y en un régimen diferente.

En medio de estos dramáticos acontecimientos se desarrolla la obra del escritor Fulvio Tomizza ${ }^{2}$, istriano nacido en 1935 en la entonces italiana Materada, municipalidad de Juricani (en italiano Giurizzani) y que ha dedicado toda su producción literaria al exilio que él mismo padeció en primera persona en 1955. Aunque vivió en Trieste hasta su muerte, acaecida en 1999, los últimos años de su vida regresó a Istria que, tras la desmembración de Yugoslavia en 1991, pasó a formar parte del nuevo estado de Croacia.

Con apenas veinticinco años publica Materada (1960), el nombre de su pueblo natal, novela que, más tarde, sería el primer libro de la Trilogia istriana, donde también se incorporan La ragazza di Petrovia (1963) e Il bosco di acacie (1966).

En Materada se cuenta la historia de una herencia. El protagonista y narrador es Francesco Coslovich, un hombre que cultiva junto con su familia las tierras de su tío, tierras que espera suyas algún día. Sin embargo, el tío, cercano a la muerte, dejará únicamente en herencia a sus sobrinos unos terrenos que, tras la Reforma agraria yugoslava, han pasado a formar parte del nuevo Estado comunista y que, por tanto, han perdido. Por esta razón, los sobrinos piden a su tío que haga un reparto justo.

Francesco intentará por todos los medios que le hagan justicia. Sin embargo, a pesar de que los representantes del Partido pretendan ayudarle, no lo harán por solidaridad hacia el protagonista, sino porque este conflicto les da la oportunidad de mos-

\footnotetext{
${ }^{2}$ http://www.treccani.it/enciclopedia/fulvio-tomizza/
} 
trar los valores comunistas y castigar al tío, al que ven como un patrón que abusa de su poder. Para ello, no dudarán en hacer acusaciones falsas, algo que desagradará a Francesco, que comprueba que nadie está dispuesto a ayudarle sin recibir nada a cambio, mucho menos el propio Partido, al que juzga abiertamente.

Al final, siguiendo el ejemplo de muchos paisanos, aceptará la propuesta del Gobierno Italiano de exiliarse en la vecina Trieste para comenzar una nueva vida.

El año en el que se desarrolla la acción de esta novela es 1955, un año después de que la Zona B del Territorio Libre de Trieste pase oficialmente a formar parte de Yugoslavia. Sin embargo, los ciudadanos de este lugar ya llevaban diez años conviviendo con el Comunismo de Tito, que en un primer momento acentuó aún más las tensiones entre eslavos e italianos de la región.

El pueblo de Materada, al igual que otros tantos de Istria, se caracteriza por una población mixta donde la mayoría habla indistintamente una lengua u otra (dialecto italiano o sudeslavo) y donde los nombres y apellidos tienen distinto origen. De esta manera, el protagonista es un gran ejemplo de híbrido istriano: tiene un nombre italiano, Francesco y un apellido eslavo, Kozlović, italianizado como Coslovich. También dependiendo de quién sea su interlocutor, se le llama con el diminutivo italiano Cesco o con el nombre en alemán Franz, ya que su infancia la pasó en la época en la que Istria pertenecía a Austria, lo que muestra la importancia histórica de la Península en las vidas de sus habitantes.

Con la mayoría de los personajes, Francesco habla italiano, aunque en el hogar lo hace en dialecto eslavo, po našu (alla nostra) (Tomizza 2008: 22).

El mismo Fulvio Tomizza hace referencia a la realidad lingüística de este personaje, que no es otra que la suya propia, en una de las conferencias recogidas en el libro póstumo titulado Alle spalle di Trieste:

Tant'è vero che il protagonista del romanzo Materada a un certo punto della vicenda narra di essersi accostato alla moglie e di averle parlato «po našu», alla nostra. Con ciò egli intendeva significare di essere risalito con la consorte, nell'intimità della casa, alla prima e vera fonte del loro esprimersi, che non consentiva reticenze né abbellimenti né infingimenti. Per me, autore allore ventitreenne, quel «po našu» era stato come un avvertimento col quale dichiaravo che fino a quel momento la narrazione di quei luoghi e di quei personaggi era stata resa attraverso una lingua il più possibile aderente alla nostra parlata, ma che restava ad ogni modo un'espressione esterna, voluta dal di fuori (Tomizza 2015: 190-191).

Es importante puntualizar que este personaje no se decanta más por una identidad que por otra, sino que acepta con normalidad su condición mixta. De este modo, a pesar de sus orígenes, lucha en la guerra contra los fascistas italianos, ayudando a los partisanos yugoslavos a liberar el país. No obstante, no todos los istrianos aceptan esta condición doblemente identitaria y ya desde los tiempos de Austria existía rivalidad entre italianos y eslavos. Sin embargo, en este momento histórico no solamente se acentúa la enemistad entre estos grupos etnolingüísticos, sino también entre aquellos que apoyan el nuevo gobierno yugoslavo comunista y aquellos que desean que Istria vuelva a Italia o, simplemente, aquellos que quieren comenzar una nueva vida en Trieste bajo el amparo del Gobierno italiano y aquellos que ven en esto una huida. 
Por otro lado, el protagonista hace una reflexión durante toda la novela sobre el cambio que el Comunismo hace en su pueblo y con sus paisanos, una consecuencia de la Segunda Guerra Mundial propia de su tierra. Piensa

che quella era stata la guerra, la guerra per tutti. Ma che dopo c'era stata un'altra guerra, riservata a noi soli, la quale aveva avuto anch'essa i suoi morti, i suoi dolori, ed aveva avuto inizio proprio quando tutto il mondo gridava alla pace e alla liberazione; quando i partigiani erano usciti dai boschi, avevano sfilato per le vie di Buje e di Umago lanciando all'aria i berretti, e si era istituito il nuovo regime (Tomizza 2008: 28-29).

En primer lugar, se ve la amenaza vigente por parte de los eslavos pertenecientes al Comité del Partido (a los que llaman druži, plural italianizado del vocativo serbo-croata druže, camarada) (Tomizza 2008: 16) para que el pueblo acepte el paso de la Zona B a Yugoslavia.

Cosí anche nel '48, quando doveva passare la delegazione alleata per stabilire i confini dell'Istria e non si vedeva una bandiera italiana neanche di quelle con la stella rossa, c'erano dappertutto scritte «vogliamo la Jugoslavia» e «qui siamo tutti croati» [...] (Tomizza 2008: 75).

Dos años más tarde, se realizaron unas elecciones propuestas por los países aliados para que el pueblo istriano, en referéndum, expresara si quería la anexión con Yugoslavia:

Erano le prime elezioni che si tenevano nel nostro distretto dacché era finita la guerra e si era istituito il nuovo regime; da esse poteva dipendere il destino delle nostre terre: Italia o Jugoslavia. Naturalmente c'era una lista unica, e andare alle urne significava già votare per il nuovo regime [...] Passavano davanti le case battendo forte sui vetri e gridando in slavo: «A morte i fascisti! Chi non vota è un fascista! Noi ammazziamo tutti i fascisti!» (Tomizza 2008: 36).

El propio Francesco ve cómo sus propios paisanos amenazan e incluso ejercen violencia física contra aquellos sospechosos de italofilia.

Tomizza destaca que, con este nuevo régimen, también cambiaron las fiestas. De esta manera, se sustituyeron las religiosas por otras como el 1 de Mayo, el día de la Liberación o el cumpleaños de Tito, no permitiendo festejarse ni la Navidad ni la Pascua: «Il Primo Maggio, per forza o per amore, era per noi diventato Natale e Pasqua, l'Ascensione e il Corpus Domini» (Tomizza 2008: 76).

Si capiva che questo era un regime diverso da tutti quelli che avevamo avuti, noi e i nostri vecchi, fino allora. Non bastava loro far soldi, volevano qualcosa di più; e lasciavano la sala al buio e la gente col portafoglio pieno per San Martino quando si prendevano i soldi dell'uva, e mettevano nastri e lampioni colorati nel Dom non per il Carnevale, ma nelle domeniche di Quaresima e di Avvento (Tomizza 2008: 30).

En otra conferencia, Tomizza dice del régimen titoísta que: 
Era comunista e perciò contrario a ogni forma di proprietà e di religione; sciovinista e dunque lanciato contro l'etnia più odiosa, che per secoli aveva umiliato la sua, durante il ventennio fascista la aveva calpestata, nel recente conflitto combattuta invano, ora pur nel terrore della sconfitta continuaba a demolirla (Tomizza 2015: 139).

En Materada se ve cómo la guerra y la llegada del Comunismo yugoslavo, que favorece a los eslavos de la zona, ha dividido y enfrentado aún más a la población. Una nueva muestra de que los paisanos de Francesco han cambiado con el nuevo régimen es que sus vecinos, que antaño se dejaban ver poco en las fiestas, ahora se muestran enfervorecidos en las nuevas celebraciones y asisten a todos los bailes que se organizan en el Dom (Casa del Pueblo) con el fin de no ser considerados enemigos del Partido (Tomizza 2008: 79). La máscara que se colocan estos personajes hace que el protagonista no pueda fiarse de nadie, ya que no conoce la opinión real de muchos de ellos.

Además, todos estos personajes con diferentes mentalidades confluyen en espacios comunes como el Dom y, sobre todo, la hostería de Gelmo. Los parroquianos, a su vez, han cambiado con la guerra: ya no se frecuentan las mismas amistades ni se ocupa el mismo lugar en este espacio antes del conflicto. De hecho, en cierta ocasión, al hablar con algún vecino con el que se había enfriado la relación, el protagonista considera que «ritornava un po' l'aria di prima della guerra quando eravamo sotto l'Italia» (Tomizza 2008: 48). Ya habían pasado diez años después de la Liberación de Yugoslavia y con la firma del Memorándum de Londres (1954), el Gobierno yugoslavo había disminuido en cierto modo las tensiones con la población italófona, siempre y cuando esta aceptara el nuevo régimen. Según cuentan los personajes, ahora se podía hablar italiano abiertamente, algo que, años atrás, podía suponer una acusación por enemigo del pueblo:

L'intricata questione di Trieste, bene o male, era stata oramai risolta. Pochi mesi prima, nel novembre del '54, i ministri avevano firmato il Memorandum di Londra, secondo il quale Trieste ritornava all'Italia, la Zona B passava definitivamente alla Jugoslavia. La gente, alla quale non accomodava di restare, poteva prendersi le sue poche robe e andarsene in Italia: si poteva optare liberamente. E i nostri capi si erano abbastanza acquetati, e a quei ragazzi ora era concesso di cantare liberamente una barcarola mentre negli anni passati guai a cantare in italiano, ciò voleva dire già far propaganda, e appunto una delle ventiquattro accuse contro Nando era stata quella di aver cantato in osteria da Gelmo «Santa Lucia» quasi per sfidare quelli che all'altro tavolo si erano messi a cantare «Mi smo pa Istranci, hrvati pravi» (Noi siamo Istriani, veri croati» (Tomizza 2008: 33).

En contraposición, los eslavos del bar bailan el kolo, danza tradicional y, bajo una estrella roja, cantan en croata canciones que nunca se habían escuchado antes. El hecho de que Tomizza indique que se canta o se habla en croata y no en el dialecto eslavo es muy característico, ya que muestra que la población no es autóctona, sino que ha llegado del interior de Croacia para repoblar, homogeneizar y «eslavizar» Istria. El mismo dueño de la hostería, Gelmo, a pesar de no hablar con fluidez este croata estandarizado, atiende a sus clientes en esta lengua: 
«Molim ljepo, drugui, izvolite!» (Prego tanto, compagni, favorite!).

Aveva imparato queste quattro parole di croato e le usava con ogni persona foresta che era di passaggio a bersi il quarto. [...] Io gli diedi un'occhiata, ma senza nessuna intenzione (anche se lo slavo che ora parlava lui era una cosa e quello che parlavamo noi in familia era un'altra), ed egli cambiò disco. «Allora, Franz mio, come va?» disse in italiano. (Tomizza 2008: 31).

Gracias a esta actitud favorable y cercana a los eslavos y, por tanto, al nuevo Gobierno, Gelmo consigue que la hostería siga siendo suya y que no haya tenido problemas de propiedad con Asuntos Internos.

Tomizza afirma que para prosperar en Yugoslavia era necesario hacer como este personaje y colaborar con el Partido:

Il turbine tuttavia si scatenava proprio nei paesi rurali dell'interno, quale il mio, chiamati a dar man forte al nuovo potere per la loro parziale appartenenza all'etnia slava, il loro isolamento tribolato, la secolare rassegnazione allo sfruttamento e all'oltraggio acuitisi durante la dittatura fascista, Là non era consentito assumere un atteggiamento passivo né prudente, bisognava collaborare magari attraverso la molestia e la denuncia segreta contro un paesano, anche parente, in maggior agio economico, di più marcato sentimento religioso, propenso al ritorno dell'Italia o soltanto alla costituzione dello staterello autonomo con a capo Trieste (Tomizza 2015: 64).

Por ello, este nuevo orden ha permitido venganzas personales, permitiendo que algunos vecinos denunciaran a paisanos con los que tenían cuentas pendientes, precisamente lo que se pretendía del protagonista. Como se ha comentado, se crea una nueva Reforma Agraria que favorece a los colonos de las tierras (especialmente si apoyan el Comunismo), permitiéndoles beneficiarse de los productos, mientras que los propietarios, aparte de tener que pagar una enorme subida de impuestos por sus tierras, no pueden disfrutar de ellos (Tomizza 2008: 18).

Este es el principal problema con el que se enfrenta el protagonista. Una tierra que no puede heredar porque ha pasado a formar parte del Estado y el terreno de su tío lo heredará su primo, que vive en Trieste.

Francesco quiere arreglar el asunto de la herencia legalmente y para ello se entrevista con el Secretario del Partido. La primera pregunta que le hacen, tuteándole, es si está afiliado. Ante la negativa, el funcionario vuelve al usted y le propone diversas ofertas, como hacerle entrega de otros terrenos de un hombre que ha emigrado a Italia. Francesco lo rechaza, ya que algún día, en caso de que el Comunismo cayera, ese terreno lo podría reclamar el propietario. Aquí se abre una reflexión muy interesante por parte del protagonista acerca del destino de Istria, territorio situado en un cruce de caminos en el que diversos imperios han instaurado su poder durante siglos:

Da quando mi ricordo, qui da noi sono venuti dapprima gli austriaci, poi gli italiani, dopo i tedeschi; infine siete venuti voialtri. Tutti se ne sono andati, ed erano più forti di voi. Io stesso ho visto cadere prima l'aquila, poi il fascio e la croce uncinata. Perché un giorno non dovrebbe cadere anche la face e il martello? (Tomizza 2008: 90). 
Como se ha comentado anteriormente, el Comité del Partido mostrará interés en ayudar a Francesco, pero no por hacerle justicia, sino para mostrar su poder. El tío, a pesar de considerarse croata, al fin y al cabo representaba a los dueños de grandes latifundios y, por tanto, era un gran objetivo a combatir por parte del Comunismo. Por ello, no dudarán en ejercerle violencia e, incluso, redactar una denuncia en la que se alegaban delitos falsos con el fin de poder arrebatarle las tierras, ya que, legalmente, todo estaba en regla y nada podía hacerse.

Francesco, que no está de acuerdo con esta política de venganzas personales y que no pretende colaborar con el Partido, emite una condena ante el Comité, acusándolos de favoritismos, de incompetentes y de que el pueblo se esté marchando a Trieste. Como respuesta a esta ofensa, uno de los asistentes se levanta y le da una bofetada. Este acto encierra una gran simbología, ya que en la guerra un fascista italiano ya le había golpeado por hablar en eslavo (Tomizza 2008: 41). Ahora se la daba un paisano comunista que, paradójicamente, era la misma persona que iba a quedarse con la tierra expropiada del protagonista. De este modo, la identidad híbrida de Francesco se ha visto golpeada en diversos momentos de la Historia por aquellos que se le presentaban como benefactores.

Es en ese momento en el que el protagonista decide que debe marcharse con su familia a Italia. En una conversación con su hermano, le dice:

Abbiamo da pensare ai nostri figli, noi due; e loro che istruzione hanno da avere rimanendo o entrando in qualche skupčina o che so io? Ha ragione barba Nin: noi non siamo per questo regime. Forse ci vuole altro fegato. Oppure ci si fa un poco alla volta, ma io questo non voglio; io di questo ho paura. Hai visto? Volevano che firmassi quella carta per mettere in disgrazia un uomo (Tomizza 2008: 136).

Como puede comprobarse, el exilio de miles de ítalo-istrianos no fue provocado únicamente porque Istria, último territorio de la Italia balcánica, pasara a Yugoslavia, sino sobre todo por el hecho de que permanecer en ese país suponía tener que colaborar con el Comunismo titoísta para aspirar a una vida mejor.

En cuestión de identidad, cualquiera de las opciones, Italia o Yugoslavia, suponía, además, renunciar de algún modo a los orígenes, italianos y eslavos, ya que en Yugoslavia serían considerados «talianazi» y en Italia «s'ciavi» ${ }^{3}$. Tomizza critica esta situación, ya que era un firme defensor de la hibridez cultural istriana que Austria, sin embargo, permitía: «Ero italiano e slavo, in definitiva né italiano né slavo, ma «altro»: un ibrido, nato libero e benestante in un angolo di campagna rigoglioso ma umilissimo» (Tomizza 2015: 65).

La novela termina cuando en Materada suenan las campanas de la iglesia en la fiesta de la Virgen de las Nieves, patrona del pueblo, día en el que, antes de la llegada del Comunismo, se bendecían los campos. Quien llama a la oración es un veci-

3 «Talianazi» era la manera despectiva de llamar a los italianos en Yugoslavia, haciendo referencia al fascismo, mientras que «s'ciavi» (esclavos) indica peyorativamente el origen etimológico de los eslavos (Tomizza 2015: 205). 
no que, junto con los demás parroquianos, entona cantos litúrgicos y abre una procesión que finalizará en el cementerio, lugar de descanso de los antepasados y, por tanto, de sus propios orígenes. En este espacio de muerte y descanso se separa la población de su tierra istriana, abandonada por Trieste, unida al lamento de una mujer que grita «Addio ai nostri morti» (Tomizza 2008: 173), motivo recurrente en las novelas de exilio, lo que acentúa el drama de las minorías que, en un momento concreto de la Historia, no han encajado ni en la ideología ni en la demografía de un estado.

\section{Referencias bibliográficas}

HAJDÚ, Zoltán (2007). Southeast-Europe: State Borders, Cross-border Relations, Spatial Structures. pp. 3-8. Pécs: MTA RKK.

TOMAZ, Luigi (2007): Il confine d'Italia in Istria e Dalmazia: duemila anni di storia. Conselve (Padova): Think ADV, stamp.

TomizzA, Fulvio (2008): Materada. Bologna: Bompiani.

- (2015): Alle spalle di Trieste. Bologna: Bompiani.

\section{Recursos electrónicos}

Imagen Página 1. http://mttj-viajesyexperiencias.blogspot.com.es/2011/05/un-corazon-llamado-istria.html (Consultado el 29 de junio de 2016).

Imagen Página 2. http://www.unafinestrasutrieste.it/storia04.htm (Consultado el 27 de junio de 2016).

http://www.treccani.it/enciclopedia/fulvio-tomizza/ (Consultado el 23 de junio de 2016). 